OPEN ACCESS

Edited by:

Luciane Cruz Lopes,

University of Sorocaba, Brazil

Reviewed by:

Niccolò Lombardi,

University of Florence, Italy

Jan Bewersdorf

Yale University, United States

*Correspondence:

Zheng Ge

zhengge@seu.edu.cn

tORCID:

Zheng $\mathrm{Ge}$

orcid.org/0000-0002-5925-2996

Specialty section:

This article was submitted to Drugs Outcomes Research and

Policies,

a section of the journa

Frontiers in Pharmacology

Received: 28 April 2021

Accepted: 14 July 2021

Published: 17 August 2021

Citation:

Ma J and Ge Z (2021) Comparison Between Decitabine and Azacitidine for Patients With Acute Myeloid Leukemia and Higher-Risk Myelodysplastic Syndrome: A Systematic Review and

Network Meta-Analysis.

Front. Pharmacol. 12:701690. doi: 10.3389/fphar.2021.701690

\section{Comparison Between Decitabine and Azacitidine for Patients With Acute Myeloid Leukemia and Higher-Risk Myelodysplastic Syndrome: A Systematic Review and Network Meta-Analysis}

\author{
Jiale $\mathrm{Ma}^{1,2}$ and Zheng $\mathrm{Ge}^{1 * t}$
}

${ }^{1}$ Department of Hematology, Zhongda Hospital, School of Medicine, Southeast University, Institute of Hematology Southeast University, Nanjing, China, ${ }^{2}$ Department of Hematology, Xuzhou Central Hospital, Xuzhou, China

Background: The hypomethylating agents (HMAs) azacitidine (AZA) and decitabine (DAC) have been widely used in patients with acute myeloid leukemia (AML) and higher-risk myelodysplastic syndrome (HR-MDS). However, few direct clinical trials have been carried out to compare the efficacy and adverse events (AEs) between these two agents. The clinical choice between them is controversial. A systematic review and network metaanalysis (NMA) was performed to compare the efficacy, safety, and survival of DAC and AZA in AML and HR-MDS patients.

Methods: We systematically searched MEDLINE, Embase, Web of Science, and Cochrane Library through March 15, 2021. Randomized controlled trials (RCTs) on AML or HR-MDS patients comparing the efficacy and safety between DAC and AZA or comparing one of HMAs to conventional care regimens (CCR) were selected.

Results: Eight RCTs $(n=2,184)$ were identified in the NMA. Four trials compared AZA to $\mathrm{CCR}$, and four compared DAC to CCR. Direct comparisons indicated that, compared to CCR, both AZA and DAC were associated with higher overall response $(O R)$ rate (AZA vs. CCR: relative risk $(R R)=1.48,95 \% \mathrm{Cl} 1.05-2.1$; DAC vs. CCR: $\mathrm{RR}=2.14,95 \% \mathrm{Cl}$ 1.21-3.79) and longer overall survival (OS) (AZA vs. CCR: $\mathrm{HR}=0.64,95 \% \mathrm{Cl} 0.50-0.82$; DAC vs. CCR: $H R=0.84,95 \% \mathrm{Cl} 0.72-0.98)$, and AZA showed higher rate of complete remission with incomplete blood count recovery (CRi) $(H R=2.52,95 \% \mathrm{Cl} 1.27-5)$. For the indirect method, DAC showed a higher complete remission (CR) rate than AZA in patients with both $\mathrm{AML}(\mathrm{RR}=2.28,95 \% \mathrm{Cl} 1.12-4.65)$ and $\mathrm{MDS}(\mathrm{RR}=7.57,95 \% \mathrm{Cl} 1.26-45.54)$. Additionally, DAC significantly increased the risk of $3 / 4$ grade anemia $(R R=1.61,95 \% \mathrm{Cl}$ : 1.03-2.51), febrile neutropenia $(R R=4.03,95 \% \mathrm{Cl}: 1.41-11.52)$, and leukopenia $(R R=$ $3.43,95 \% \mathrm{Cl} 1.64-7.16)$ compared with AZA. No statistical significance was found for the other studied outcomes.

Conclusion: Compared to CCR, both AZA and DAC can promote outcomes in patients with $A M L$ and HR-MDS. DAC showed higher efficacy especially CR rate than AZA (low- 
certainty evidence), while AZA experienced lower frequent grade 3/4 cytopenia than patients receiving DAC treatment.

Keywords: decitabine, azacitidine, acute myeloid leukemia, higher-risk myelodysplastic syndrome, network metaanalysis

\section{INTRODUCTION}

Acute myeloid leukemia (AML) and higher-risk myelodysplastic syndromes (HR-MDS) are heterogeneous hematologic malignancies with clinical manifestations of anemia, hemorrhage, and infection (Arber, 2019). HR-MDS are defined as patients with intermediate-2 or high-risk score by the International Prognostic Scoring System (IPSS) or with intermediate, high, or very high-risk score by the Revised International Prognostic Scoring System (IPSS-R) (Pfeilstocker et al., 2016). HR-MDS are aggressive disorders with rapid progression to $\mathrm{AML}$, with a poor prognosis despite intensive chemotherapy (IC). The annual incidence rates of AML are higher than 4.2 per 100,000 per year (Shallis et al.,2019). The 2- and 5-year overall survival (OS) rates of elderly AML patients are approximately 10 and 2\%, respectively (Menzin et al., 2002; Daly and Paquette, 2019). Allogeneic hematopoietic stem cell transplantation (alloHSCT) is considered to be the only curative treatment for HRMDS and AML (Stone, 2009). Limited by HLA-matching donor, physical status, ages, costs, treatment-related mortality (TRM), and graft-versus-host disease (GVHD), many patients are ineligible for allo-HSCT. Therefore, it is urgent to develop an effective therapeutic approach for these patients who are ineligible for transplantation.

Azacitidine (AZA) and decitabine (DAC) are lower-intensity chemotherapy agents and have been approved to treat MDS by the Food and Drug Administration (FDA). On September 1, 2020, FDA approved oral AZA for the maintenance treatment of patients with AML. Hypomethylating agents (HMAs) have become the standard therapy for patients with HR-MDS or AML who are not candidates for allo-HSCT and intensive chemotherapies (Sanz, 2019). These two agents are slightly different in structure: AZA is a ribonucleoside, while DAC is a deoxyribonucleoside (Lyko and Brown, 2005). Both AZA and DAC act by depletion of DNA methyltransferases. However, these two agents have different mechanisms of action: $80-90 \%$ of AZA is integrated into RNA, leading to abnormal ribosome assembly and inhibiting tumor-related protein synthesis; $10 \%-20 \%$ can also be converted into 5-aza-2'-deoxycytidine by the action of ribonucleotide reductase to bind to DNA, thereby inhibiting DNA methyltransferase and leading to the reexpression of tumor suppressor genes. While DAC is incorporated only into DNA, high-dose DAC inhibits DNA cross-linking and synthesis through cytotoxicity, and low-dose DAC exerts DNA demethylation by inhibiting DNA methyltransferase, reactivating silent tumor suppressor genes (Stresemann and Lyko, 2008; Hollenbach et al., 2010). Preclinical studies have shown that DAC is more effective than AZA in antileukemia activity in vivo (Cany et al., 2018); however, clinical data indicate that AZA is more effective than DAC. Observational studies of these two agents have shown similar efficacy and toxicity profiles in the treatment of refractory anemia with excessive blasts (MDS-RAEB) (Salim et al., 2016). Compared with CCR, both AZA and DAC have shown delayed progression to AML (Fenaux et al., 2009; Kantarjian et al., 2006; Lubbert et al., 2011; Silverman et al., 2002). However, only AZA has shown a significant advantage in OS compared with CCR (median OS, 24.5 vs. 15 months, respectively) in patients with HR-MDS and AML with $20-30 \%$ marrow blasts (Fenaux et al., 2009), establishing it as the first-line treatment of choice for those patients who are unfit for transplant (Santini et al., 2010).

Up to now, direct comparison of AZA and DAC has been performed in rare randomized trials, leading to the dilemma choice of these two agents for patients and physicians. Several meta-analyses have been conducted to compare the efficacy and safety of AZA and DAC in MDS or AML patients. None of them made a comparison in HR-MDS and AML. Therefore, the objective of this study was to compare the efficacy, safety, and survival of AZA and DAC in patients with HR-MDS and AML.

\section{METHODS}

We prospectively registered the current review in the PROSPERO database (registration number: CRD42021245905). The Preferred Reporting Items for a Systematic Review and Meta-Analysis of Diagnostic Test Accuracy (PRISMA-DTA) studies guideline was followed in preparing this systematic review.

\section{Search Strategy}

We systematically searched all studies published in MEDLINE (via PubMed), Web of Science, Cochrane Library, and Embase through March 15, 2021, without time or language restrictions. Keywords included "hypomethylating agents", "azacitidine", "decitabine", "myelodysplastic syndrome", and "acute myeloid leukopenia". The detailed search strategies were listed in Supplementary Table S1.

\section{Study Selection, Inclusion, and Exclusion Criteria}

All randomized controlled trials (RCTs) comparing HMAs to CCR (including best supportive care (BSC), low-dose Ara-C (LDA), and IC) or AZA to DAC in patients with HR-MDS and AML were included in this study, regardless of publication status and language. Reviews, case reports, metaanalyses, and preclinical and observational studies were excluded. Two reviewers (Jiale Ma and Zheng Ge) screened all references identified through our search and inclusion criteria. Disagreements were settled by discussion of the two reviewers and involved a third independent reviewer if necessary. 


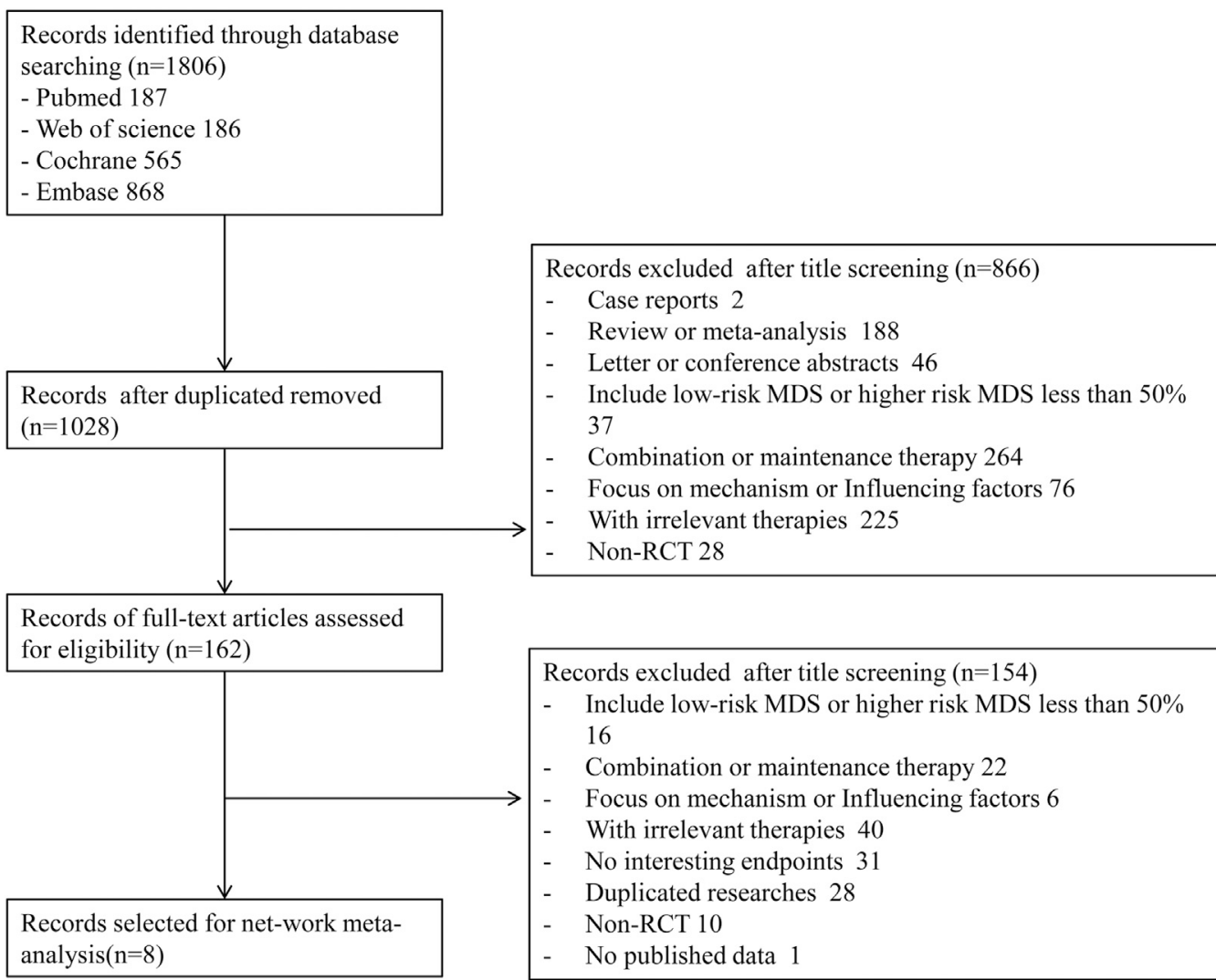

FIGURE 1 | Flowchart presenting the steps of the literature search and selection.

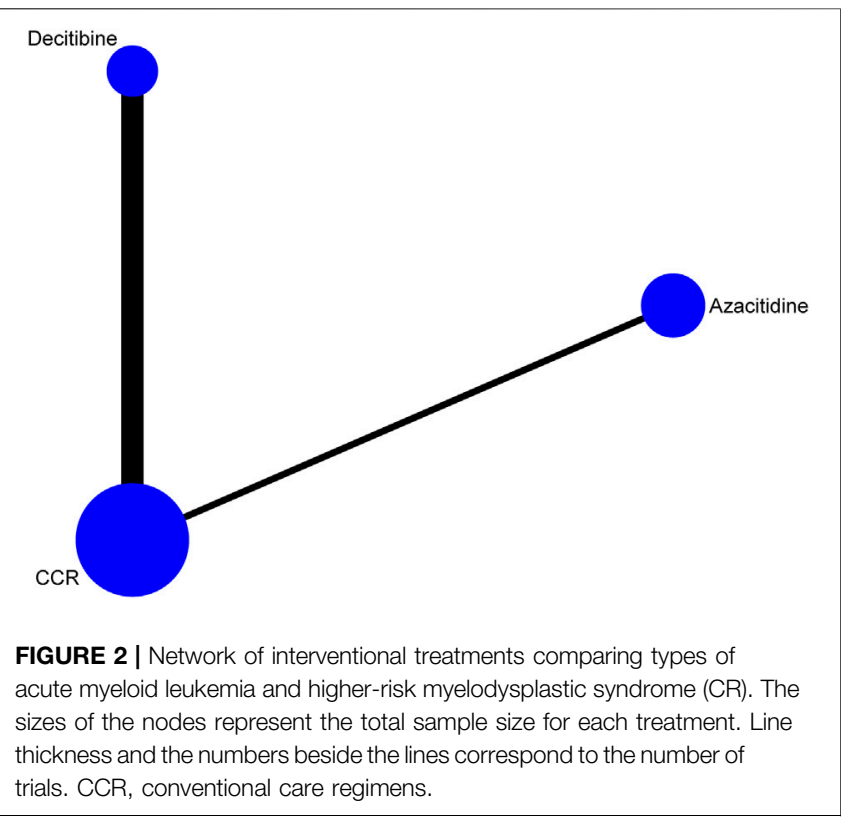

Phases II and III and RCTs were selected in this systematic review and network meta-analysis (NMA). Adult patients diagnosed with AML and/or MDS were selected. The treatment options included single agent AZA or DAC, or comparison of these two drugs against each other, or comparison of them to CCR without previous allo-HSCT or other chemotherapies. Of note, in MDS studies, the included population of higher-risk MDS should be more than $60 \%$ of all MDS patients. In other words, the included population should be mainly HR-MDS. Additionally, at least one of the relevant outcomes should be reported in the trial including objective remission (OR), complete remission (CR), complete remission with incomplete blood count recovery (CRi), complete remission with incomplete platelet recovery (CRp), partial response (PR), hematological improvement (HI), marrow complete remission $(\mathrm{mCR})$ rates, or AEs or at least one form of survival data.

Exclusion criteria included patients with therapy-related disease; prior treatment with AZA, DAC, chemotherapy, immunotherapy, or planned allo-HSCT.

\section{Date Extraction and Clinical Endpoint}

Extracted data included 1) study characteristics (author, publication year, and study type); 2) patient characteristics (age, gender, WHO/FAB classification, disease stage using IPSS criteria, karyotype risk, and ECOG score); 3) the hypomethylating treatment regimen; 4) the outcome measures [CR, CRi, CRp, PR, HI, mCR, overall response (OR) rates, drug- 


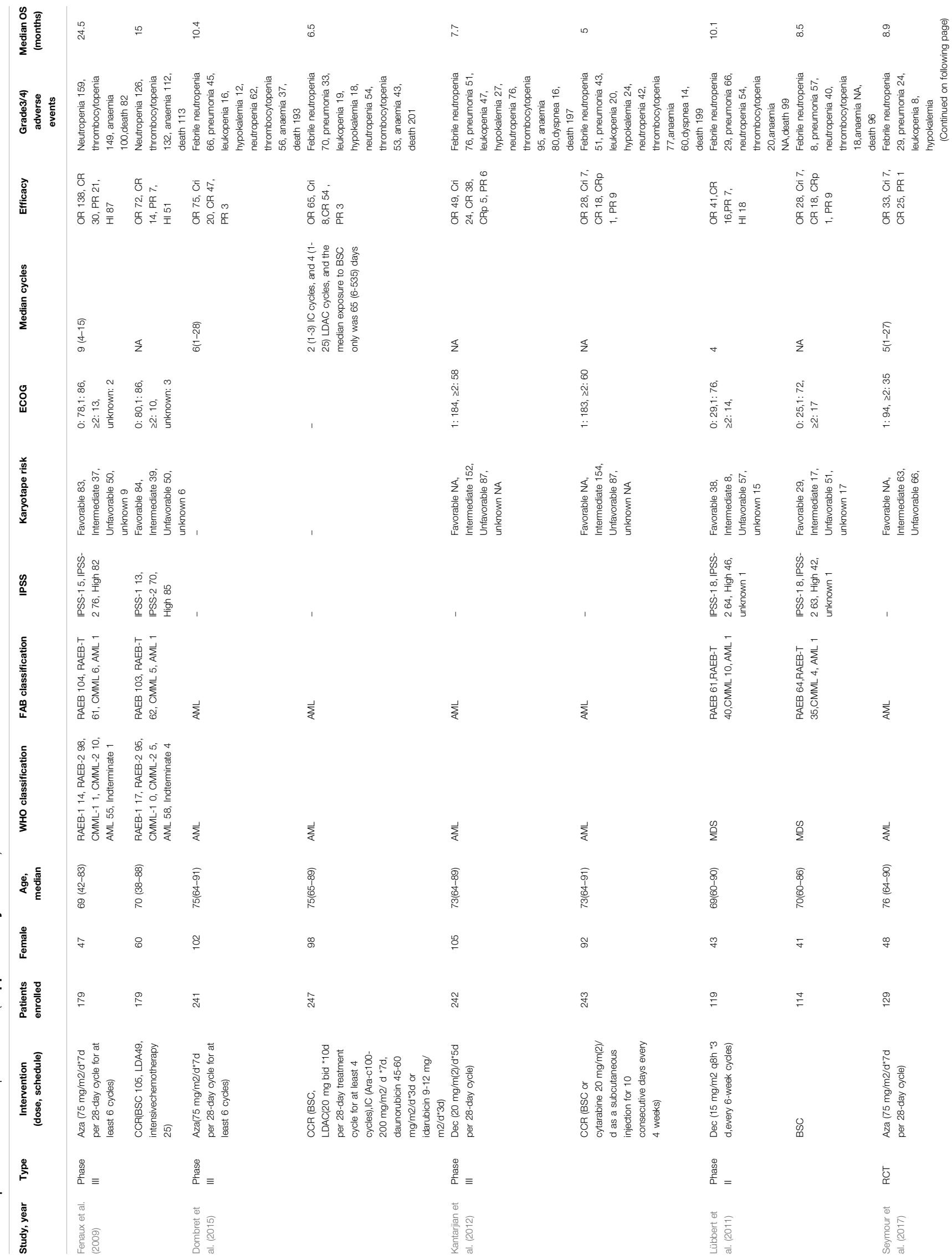


TABLE 1 | (Continued) Characteristics of publications (Supplementary Material).

\begin{tabular}{|c|c|c|c|c|c|c|c|c|c|c|c|c|c|c|}
\hline Study, year & Type & $\begin{array}{l}\text { Intervention } \\
\text { (dose, schedule) }\end{array}$ & $\begin{array}{l}\text { Patients } \\
\text { enrolled }\end{array}$ & Female & $\begin{array}{l}\text { Age, } \\
\text { median }\end{array}$ & WHO classification & FAB classification & IPSS & Karyotape risk & ECOG & Median cycles & Efficacy & $\begin{array}{c}\text { Grade3/4) } \\
\text { adverse } \\
\text { events }\end{array}$ & $\begin{array}{c}\text { Median os } \\
\text { (months) }\end{array}$ \\
\hline & & & & & & & & & & & & & $\begin{array}{l}\text { 9,neutropenia } 28, \\
\text { thrombocytopenia } \\
33 \text {,anaemia } \\
\text { 19,dyspnea } 6, \\
\text { sepsis } 7 \text {, death NA } \\
\text { Febrile neutropenia }\end{array}$ & \\
\hline & & CCR & 133 & 55 & $75(65-87)$ & AML & AML & - & $\begin{array}{l}\text { Favorable NA, } \\
\text { Intermediate } 61, \\
\text { Unfavorable } 72,\end{array}$ & $1: 104, \geq 2: 29$ & 2 & $\begin{array}{l}\text { OR 25, Cri 3, } \\
\text { CR 20, PR } 2\end{array}$ & $\begin{array}{l}\text { Febrile neutropenia } \\
43 \text {, pneumonia } \\
18, \text { leukopenia } 10, \\
\text { hypokalemia 10, } \\
\text { neutropenia } 25, \\
\text { thrombocytopenia } \\
27 \text {,anaemia } \\
21, \text { dyspnea } 4, \\
\text { sepsis } 9 \text {, death NA }\end{array}$ & 4.9 \\
\hline \multirow[t]{2}{*}{$\begin{array}{l}\text { Fenaux et al. } \\
\text { (2010) }\end{array}$} & $\begin{array}{l}\text { Phase } \\
\text { III }\end{array}$ & $\begin{array}{l}\text { Aza }\left(75 \mathrm{mg} / \mathrm{m} 2 / \mathrm{d}^{*} 7 \mathrm{~d}\right. \\
\text { per } 28 \text {-day cycle for at } \\
\text { least } 6 \text { cycles) }\end{array}$ & 55 & 18 & $70(52-80$ & AML & AML & - & $\begin{array}{l}\text { Favorable 19, } \\
\text { Intermediate } 38, \\
\text { Unfavorable 14, } \\
\text { unknown } 3\end{array}$ & $\begin{array}{l}\text { 0: } 16,1: 35 \text {, } \\
\text { 22: 4, } \\
\text { unknown } 0\end{array}$ & NA & CR 10 & $\begin{array}{l}\text { Neutropenia 50, } \\
\text { thrombocytopenia } \\
\text { 48,anaemia } \\
\text { 30,death NA }\end{array}$ & 24.5 \\
\hline & & $\mathrm{CCR}$ & 58 & 17 & $70(50-83)$ & AML & AML & - & $\begin{array}{l}\text { Favorable 33, } \\
\text { Intermediate 43, } \\
\text { Unfavorable 13, } \\
\text { unknown 2 }\end{array}$ & $\begin{array}{l}\text { 0: 22,1: } 34, \\
\text { 22: } 0 \text {, } \\
\text { unknown } 2\end{array}$ & NA & CR 9 & $\begin{array}{l}\text { Neutropenia } 44, \\
\text { thrombocytopenia } \\
\text { 44, anaemia } 36, \\
\text { death NA }\end{array}$ & 16 \\
\hline \multirow[t]{2}{*}{$\begin{array}{l}\text { Kantarijian et } \\
\text { al. (2006) }\end{array}$} & $\begin{array}{l}\text { Phase } \\
\text { III }\end{array}$ & $\begin{array}{l}\operatorname{Dec}(15 \mathrm{mg} / \mathrm{m} 2 \\
\text { q8h³d,every } 6 \text { weeks) }\end{array}$ & 89 & 30 & $70(65-76)$ & NA & $\begin{array}{l}\text { RA 12, RARS 7, } \\
\text { RAEB 47, RAEB-T } \\
17, \text { CMML } 6\end{array}$ & $\begin{array}{l}\text { IPSS-1 28, } \\
\text { IPSS-2 38, } \\
\text { High } 23\end{array}$ & NA & $\begin{array}{l}\text { 0: 21,1: 61, } \\
\text { 22: } 4 \text {, } \\
\text { unknown } 0\end{array}$ & $3(0-9)$ & $\begin{array}{l}\text { OR 27, CR 8, } \\
\text { PR 7, HI } 12\end{array}$ & $\begin{array}{l}\text { Febrile neutropenia } \\
23 \text {, pneumonia } 15, \\
\text { leukopenia } 22, \\
\text { neutropenia } 87, \\
\text { thrombocytopenia } \\
85 \text {, anaemia } 12 \text {, } \\
\text { death } 12\end{array}$ & 14 \\
\hline & & BSC & 81 & 24 & $70(62-74)$ & NA & $\begin{array}{l}\text { RA 12, RARS 4, } \\
\text { RAEB 43, RAEB-T } \\
14, \text { CMML } 8\end{array}$ & $\begin{array}{l}\text { IPSS-1 24, } \\
\text { IPSS-2 36, } \\
\text { High } 21\end{array}$ & NA & $\begin{array}{l}\text { 0: } 28,1: 48, \\
\geq 2: 4, \\
\text { unknown } 1\end{array}$ & NA & OR 6,HI 6 & $\begin{array}{l}\text { Febrile neutropenia } \\
\text { 4, penumonia 9, } \\
\text { leukopenia } \\
\text { 7,neutropenia } 50, \\
\text { thrombocytopenia } \\
43 \text {, anaemia } 15 \text {, } \\
\text { death } 18\end{array}$ & 14.9 \\
\hline \multirow[t]{2}{*}{$\begin{array}{l}\text { Becker et al. } \\
\text { (2015) }\end{array}$} & $\begin{array}{l}\text { Phase } \\
\text { III }\end{array}$ & $\begin{array}{l}\text { Dec (15 mg/m2 q8h *3 } \\
\text { d,every 6-week cycles) }\end{array}$ & 40 & 11 & $69.5(61-90)$ & MDS & RAEB-t & $\begin{array}{l}\text { IPSS-1 2, IPSS- } \\
212, \text { High } 26\end{array}$ & $\begin{array}{l}\text { Favorable 16, } \\
\text { Intermediate 4, } \\
\text { Unfavorable 14, } \\
\text { unknown } 6\end{array}$ & $\begin{array}{l}0: 8,1: 29, \\
22: 3\end{array}$ & NA & $\begin{array}{l}\text { OR 12, CR 4, } \\
\text { PR 2, HI } 6\end{array}$ & NA & 8 \\
\hline & & $\mathrm{BSC}$ & 35 & 11 & $69(61-80)$ & MDS & RAEB-t & $\begin{array}{l}\text { IPSS-1 0, IPSS- } \\
213 \text {, High } 22\end{array}$ & & $\begin{array}{l}\text { 0: } 10,1: 19, \\
22: 6\end{array}$ & NA & $\begin{array}{l}\text { OR O, CR O, } \\
\text { PR O, HI O }\end{array}$ & NA & 6 \\
\hline
\end{tabular}

AZA, azacitidine; DAC, decitabine; CCR, conventional care regimens (including best supportive care, low-dose cytarabine, and intensive chemotherapy); BSC, best supportive care; RAEB, refractory anemia with excess blasts; RAEB-T, refractory anemia with excess blasts transformation; NA, not available; $O R$, objective remission; $C R$, complete remission, CRi, complete remission with incomplete blood count recovery; CRp, complete remission with incomplete platelet recovery; $P R$, partial response; $H I$, hematological improvement; $m C R$, marrow complete remission. 

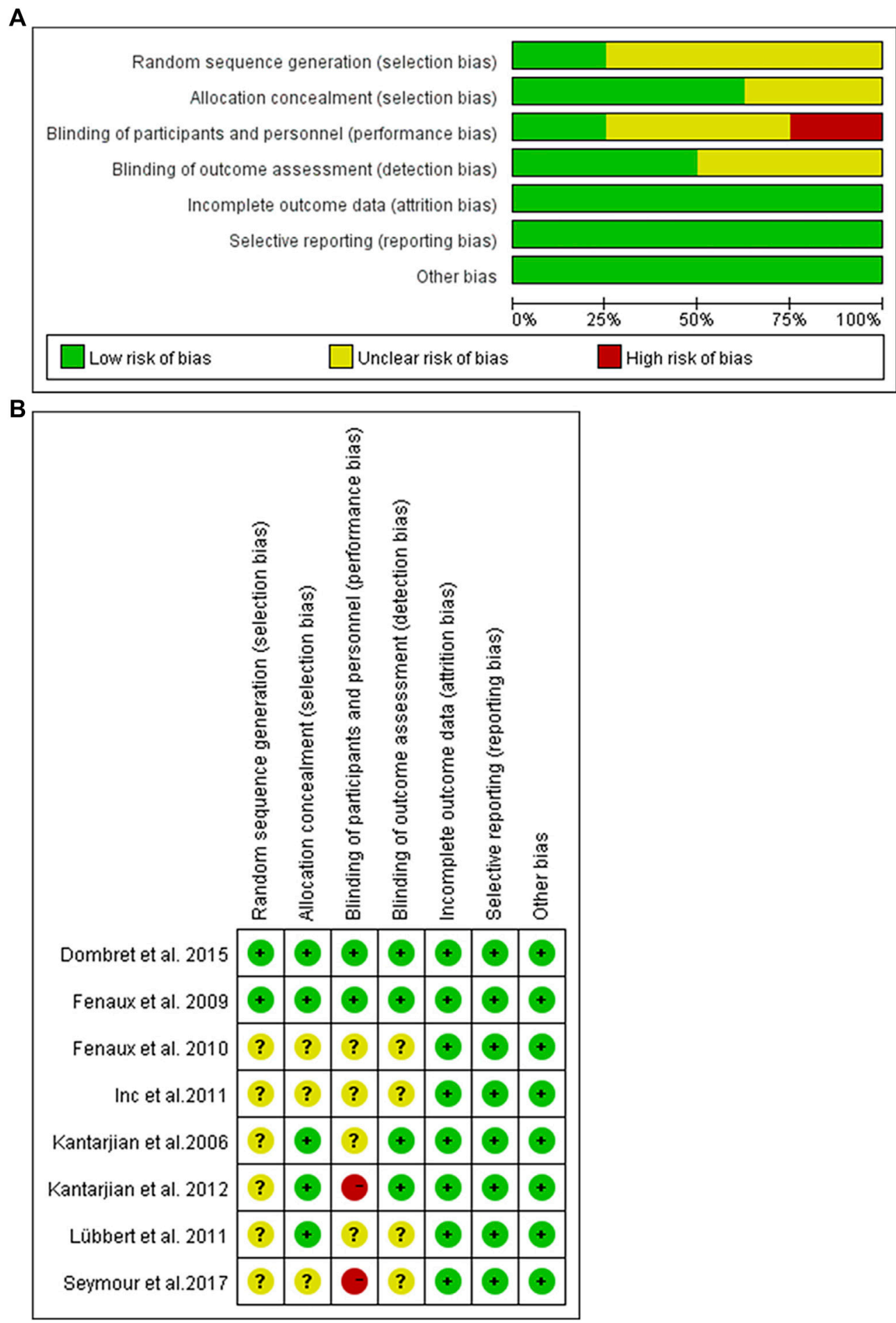

FIGURE 3|Risk of bias graph. (A) Authors' judgments about each risk of bias item presented as percentages across all included studies. (B) Risk of bias summary. Authors' judgments about each risk of bias item for each included study.

related AEs rate, and OS]. The primary outcomes were efficacy (response rate measured by a total number of included patients) and AEs. The second outcomes were OS of all patients. In the absence of information or supplemental data from the authors, the response rate was calculated according to a validated imputation method (Furukawa et al., 2005). 


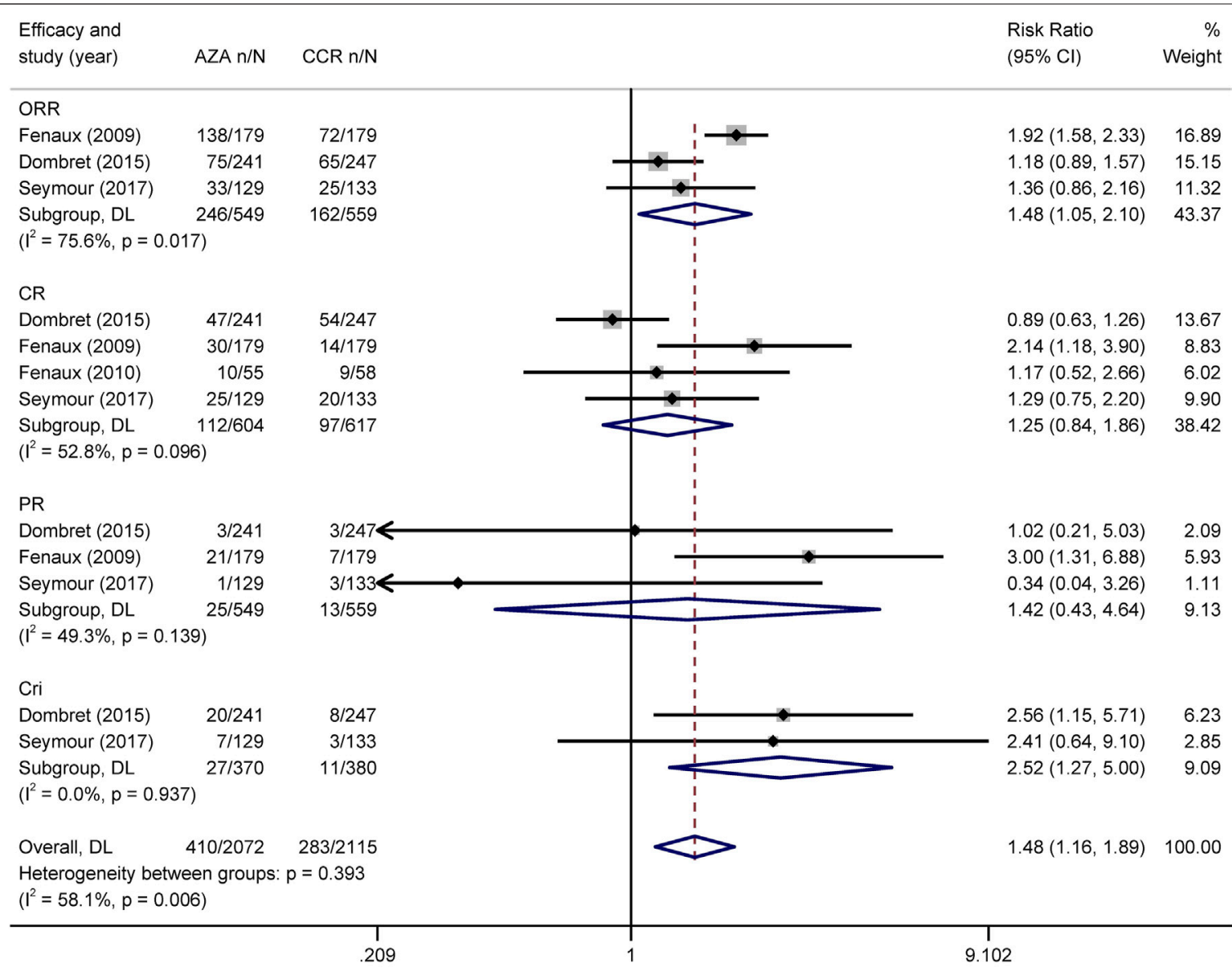

NOTE: Weights and between-subgroup heterogeneity test are from random-effects model

FIGURE 4 | Forest plot of efficacy of azacitidine vs. conventional care regimens (direct evidence-RR). Forest plot represents the direct comparison of efficacy between AZA and CCR. RR, relative risks; $95 \% \mathrm{Cls}$, 95\% confidence intervals; CCR, conventional care regimens; $\mathrm{n}$, total number of events; $\mathrm{N}$, total number of patients.

\section{Quality Assessment}

Cochrane Handbook for Systematic Reviews of Interventions was used to assess the bias of each included RCT. The criteria for evaluation included random sequence generation, allocation concealment, blinding, incomplete outcome data, selective outcome reporting, and other sources of bias. The risk of bias was assessed as low, unclear, or high.

\section{Statistical Analysis}

All the NMAs were performed by using the meta-analysis program of STATA 14.0 software (Stata Corporation, Texas) and Review Manager 5.4 software (Cochrane Collaboration, Oxford, United Kingdom). Direct pairwise meta-analyses were first performed to estimate the available relative effects of the competing interventions using the random effects model. The binomial distribution was used to calculate and express relative risks (RRs) and $95 \%$ confidence intervals (95\% CIs). Heterogeneity parameters $\left(\mathrm{I}^{2}\right)$ for each pairwise comparison were quantified to express a percentage of variability, and that is due to true differences between studies rather than sampling error (Higgins and
Thompson, 2002). All analyses were performed by using the Mantel-Haenszel (M-H) method.

We performed an NMA to analyze all comparisons among interventions for each outcome. This is because NMA takes advantage of two statistical approaches. First, the use of indirect comparisons can help us to estimate the effect of intervention A versus intervention $\mathrm{B}$, indirectly if both $\mathrm{A}$ and $\mathrm{B}$ have been compared against an intervention $\mathrm{C}$. Second, the combination of direct and indirect comparisons allows reviewers to obtain more precise estimates (Nino-Serna et al., 2020). In the presence of both direct and indirect evidence, the NMA provided a combined effect estimate. A random effects model of NMA was conducted for each outcome using the multivariate meta-analysis approach. For each outcome and a connected network of studies, we performed a frequentist framework NMA if the assumptions of between-study homogeneity, transitivity, and consistency of evidence across treatment comparisons were judged to be justifiable (Baker and Kramer, 2002; Cipriani et al., 2013). Inconsistency network models were used to test the global consistency of direct and indirect estimates for pairwise comparisons, and node-splitting 


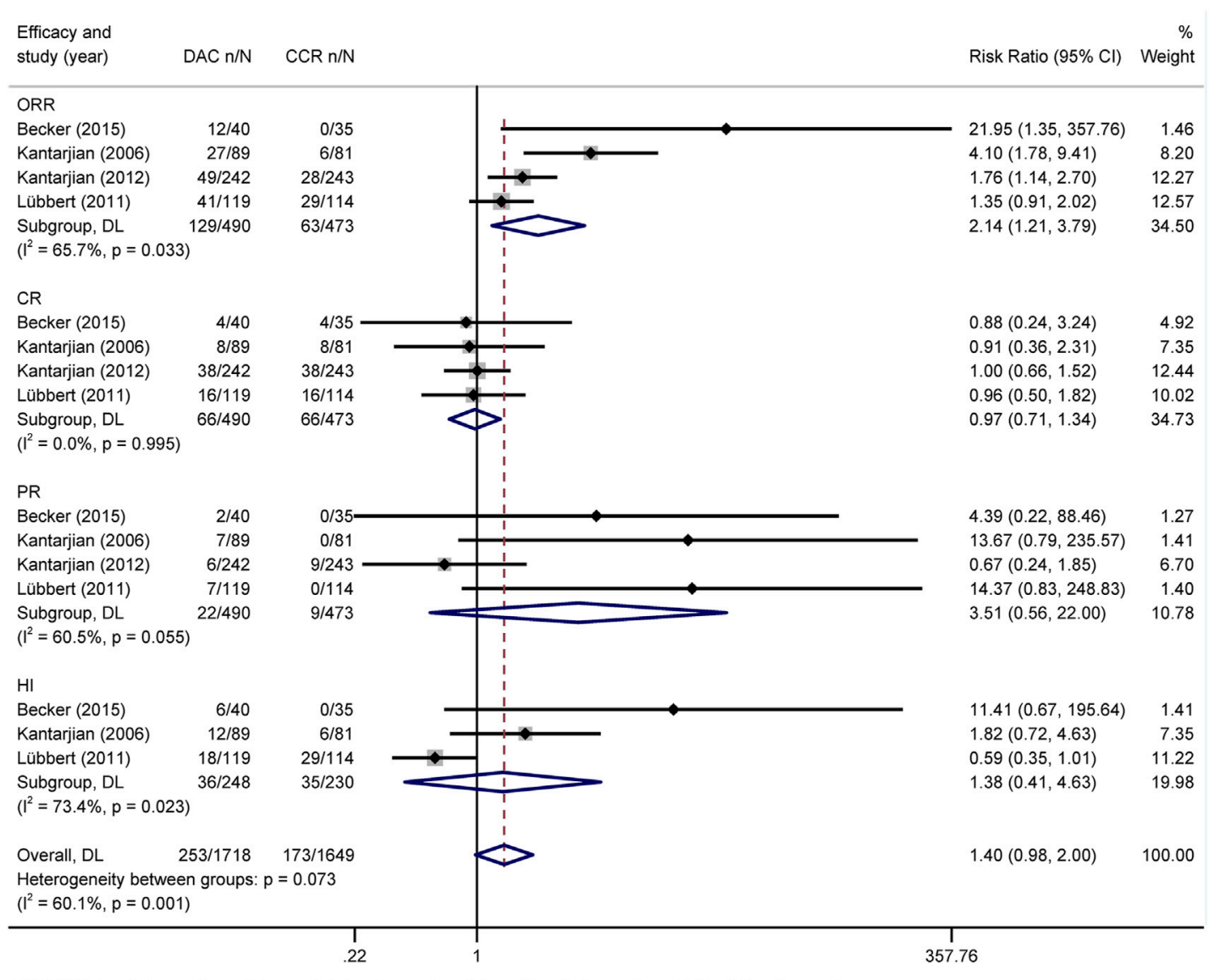

NOTE: Weights and between-subgroup heterogeneity test are from random-effects model; continuity correction applied to studies with zero cells

FIGURE 5 | Forest plot of efficacy of decitabine vs. conventional care regimens (direct evidence-RR)

method models were used to test the local inconsistency. Design-bytreatment interaction models (Higgins et al., 2012) were used to statistically evaluate the consistency. We assume that the treatment comparisons have common heterogeneity because the included treatments have the same properties and sharing common heterogeneity parameters is clinically reasonable. The graph and summary of risk of bias were created to assess the bias within studies. Surface under the cumulative ranking (SUCRA) (Salanti et al., 2011) probabilities were used to rank the treatment for the outcome. For patients with HR-MDS or AML, larger SUCRA values indicate higher rank of the treatment. In addition, a clustered ranking plot was constructed using SUCRA values for efficacy and safety outcomes to obtain information on meaningful groups of treatments that maximize benefits for efficacy and safety outcomes.

\section{RESULTS}

\section{Literature Search Results}

A total of 1,806 records were obtained with the search strategy. After removing 778 duplicates, 1,028 records were screened by title and abstract. A total of 866 records were excluded due to ineligibility. 162 records of full-text articles were assessed for eligibility. 154 records were excluded after screening full-text articles. Of note, the results of Becker et al. (2015)'s study in 2015 were a subgroup analysis of the randomized phase III study 06,011 of the EORTC Leukemia Cooperative Group and German MDS Study Group (GMDSSG) (Lubbert et al., 2011). Despite being a same study, these two articles focused on different aspects. Lubbert et al.'s study involved all riskstratified MDS patients, while Becker et al.'s study included only RAEB-t patients, which was more representative in the high-risk group. If we only include Becker et al.'s study, the other middle- and high-risk patients of the entire experimental group will be ignored. After weighing it, repeatedly, we included both studies in the statistical analysis, although it may bring selected offsets. Finally, eight trials were eligible for extraction for this NMA (Figure 1). As indicated in the network plot (Figure 2), AZA vs. CCR and DAC vs. CCR are the most prevalent comparisons.

\section{Publication Characteristics}

The characteristics of publication were listed in Table 1. Eight RCTs involved 2,184 patients with a median age of 71.1 years (IQR 68.4-73.8). Four RCTs involved a number of 1,221 patients compared to AZA ( $75 \mathrm{mg} / \mathrm{m} 2 /$ day for 7 days every 28 -day cycle for at least six cycles) and the CCR, including BSC, LDA, and I. Four RCTs involving 963 patients compared DAC (15-20 mg/ 


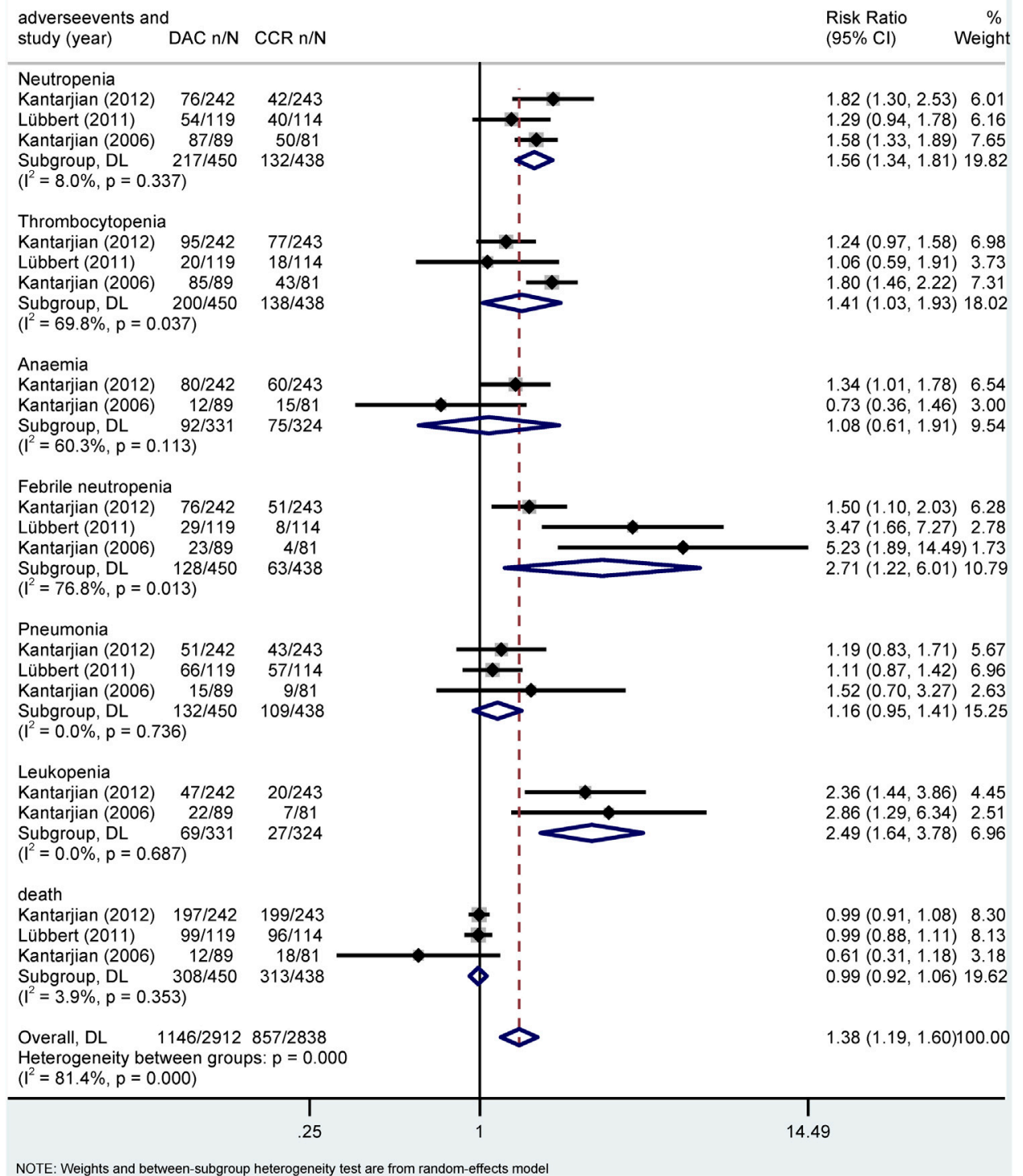

FIGURE 6 | Forest plot of efficacy represents the direct and indirect comparison.

m2/day for 3-5 days every 428 -day cycles) to CCR. Among the eight RCTs, four were about the application of HMA in MDS, and four were in AML. According to IPSS scores, more than $70 \%$ of patients had intermediate- 2 or high-risk MDS (Becker et al., 2015; Fenaux et al., 2009; Kantarjian et al., 2006; Lubbert et al., 2011; Inc E et al., 2014). The Eastern Cooperative Oncology Group (ECOG) performance status scores of patients from seven trials are between 0 and 2 . For response data, all trials with MDS applied International Working Group (IWG) 2,000 response criteria (Cheson et al., 2000), and all trials with AML applied IWG 2004 response criteria (Creutzig and Kaspers, 2004). AEs were assessed with the National Cancer Institute's Common Toxicity Criteria, version 2.0/3.0. Grade 3-4 AEs are the main research (http://ctep.cancergov/reporting/ ctc_archive.html).

\section{Risk of Bias}

The risk of bias among studies ranges from low and unclear to high. Random sequence generation was adequate in two trials, whereas allocation concealment was achieved in six trials and blinding of outcome assessor in two trials. In addition, selective reporting and incomplete outcome data were low risk in all trials. The graph and summary of the risk of bias are shown in Figure 3.

\section{Assessment of Inconsistency}

Inconsistency tests between direct and indirect estimates in AZA versus DAC were nonsignificant $(p>0.05)$, indicating that indirect estimates were not different to direct evidence. The estimation of NMA inconsistency between AZA and DAC was listed in Supplementary Table S2. The overall level of each treatment met the consistency assumption $(p>0.05)$. 
TABLE 2 | Summary of the SUCRA of efficacy and high-grade side effects.

\begin{tabular}{|c|c|c|c|c|}
\hline Outcome and data & AZA & DAC & CCR & $\begin{array}{c}p \text {-value of the } \\
\text { design-by-treatment test }\end{array}$ \\
\hline Overall response rate & 63.7 & 84.3 & 2.1 & 0.625 \\
\hline Complete remission & 44.1 & 97.6 & 8.3 & 0.074 \\
\hline Partial remission & 47.4 & 82.1 & 20.6 & 0.54 \\
\hline Complete remission with incomplete blood count recovery & 6.39 & 85.9 & 0.2 & 0.553 \\
\hline Hematology improvement & 64.7 & 55.4 & 29.8 & 0.876 \\
\hline Neutropenia & 49.9 & 0.1 & 100 & 0.005 \\
\hline Thrombocytopenia & 47.8 & 13 & 89.2 & 0.434 \\
\hline Anemia & 96 & 4.9 & 49.1 & 0.037 \\
\hline Febrile neutropenia & 97.1 & 0.3 & 62.7 & 0.009 \\
\hline Pneumonia & 16.5 & 37.6 & 91.9 & 0.589 \\
\hline Leukopenia & 86.6 & 0 & 63.4 & 0.002 \\
\hline Hypokalemia & 82.8 & 24.7 & 42.5 & 0.324 \\
\hline Death & 83 & 45.2 & 21.8 & 0.489 \\
\hline
\end{tabular}

SUCRA, surface under the cumulative ranking curve.

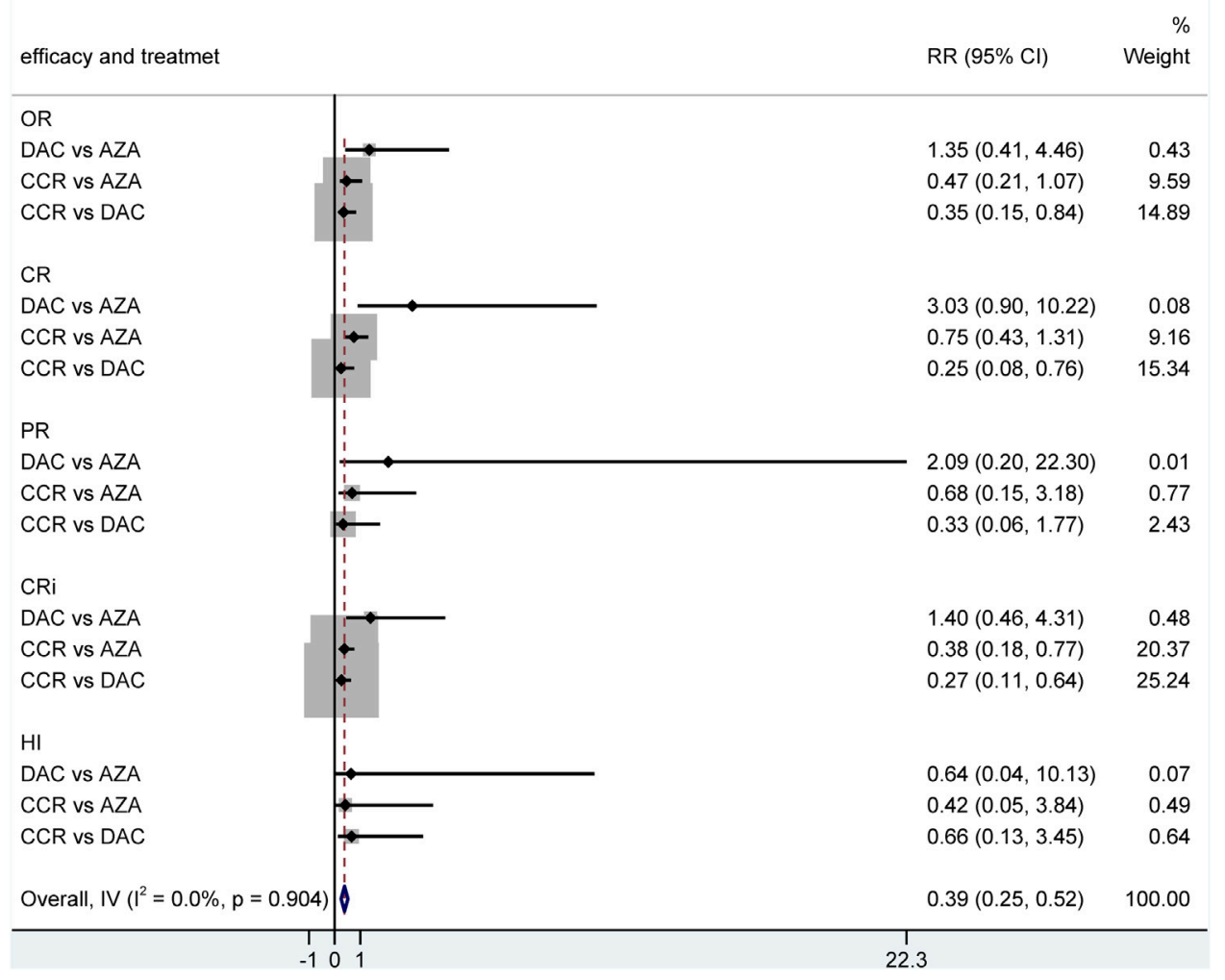

FIGURE 7 | Forest plot of grade 3/4 adverse events of azacitidine vs. conventional care regimens (direct evidence-RR).

Results of NMA

Comparison of Efficacy Between Decitabine and Azacitidine

The primary efficacy endpoints were OR, CR, PR, CRi, and HI rates. IWG 2000 response criteria were used in all patients with MDS, while IWG2003 response criteria were applied in patients with AML. Direct comparison of HMAs with CCR showed that AZA significantly increased the rates of OR $(\mathrm{RR}=$
1.48, 95\% CI 1.05-2.1) and CRi (HR $=2.52,95 \%$ CI $1.27-5)$ (Figure 4), while DAC only increased the rate of OR (RR = 2.14, 95\% CI 1.21-3.79) (Figure 5). Concerned about the high heterogeneity $\left(I^{2}>50 \%\right)$, a subgroup analysis by disease type was estimated. In AML, AZA showed a higher CRi rate than CCR ( $R R=2.52,95 \%$ CI 1.27-5.00) (Supplementary Figure S1). In MDS, DAC significantly increased the PR rate than CCR (RR $=9.78,95 \%$ CI 1.83-52.09) (Supplementary Figure 


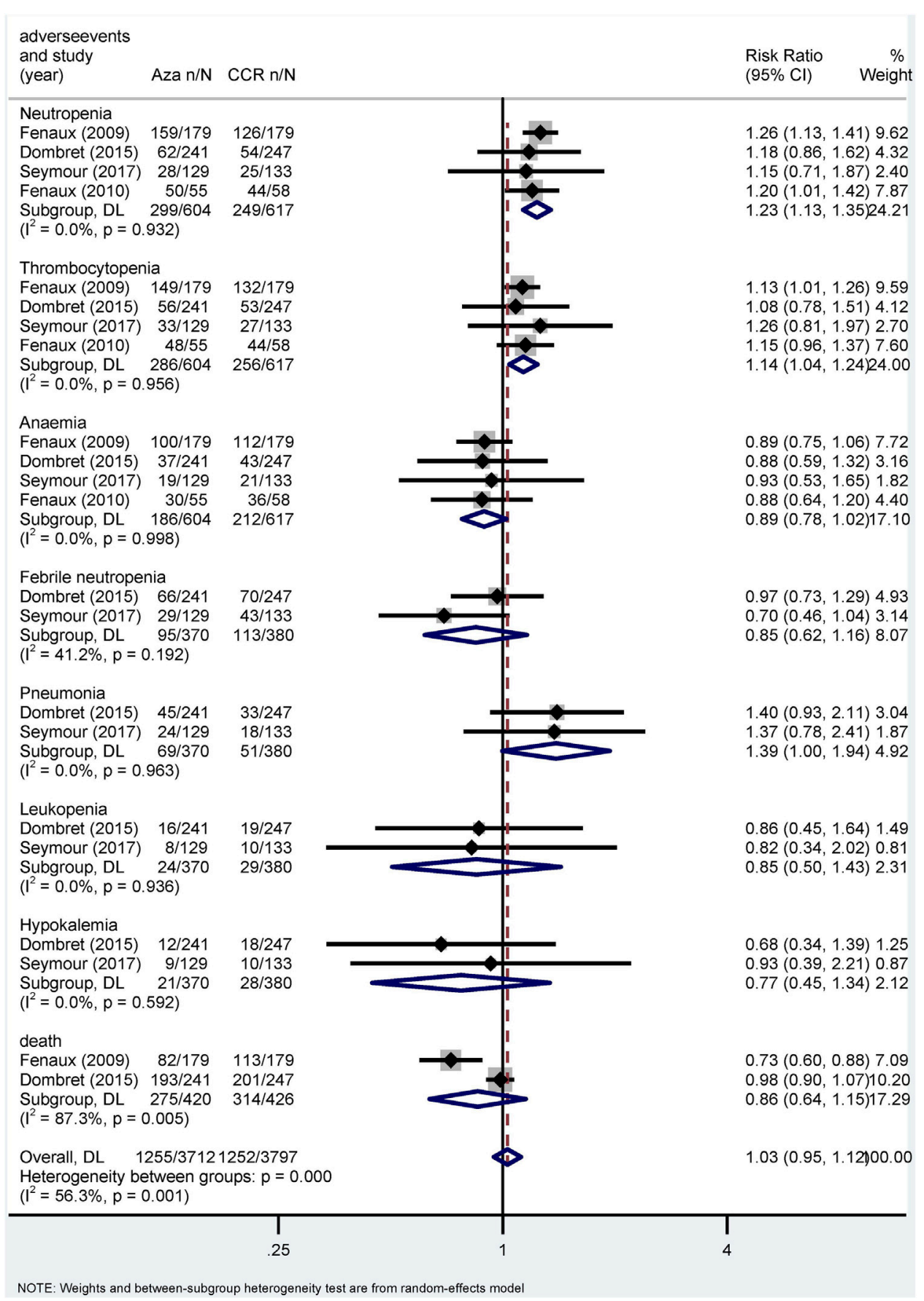

FIGURE 8 | Forest plot of grade 3/4 adverse events of decitabine vs. conventional care regimens (direct evidence-RR).

S4). There were no statistically significant differences in other outcomes.

For NMA, there were no statistically significant differences in terms of OR, CR, PR, CRi, and HI between DAC and AZA (Figure 6; Table 2). However, when performing subgroup analysis by disease type, DAC showed a higher CR rate than AZA both in AML $(\mathrm{RR}=2.28,95 \%$ CI 1.12-4.65)
(Supplementary Figure S3) and in MDS (RR $=7.57,95 \%$ CI 1.26-45.54) (Supplementary Figure S6).

\section{Comparison of Grade 3/4 Adverse Events (HTEs) Between Decitabine and Azacitidine}

Hematological toxicity was the most common adverse event in HMA treatment, which included leukopenia, neutropenia, 


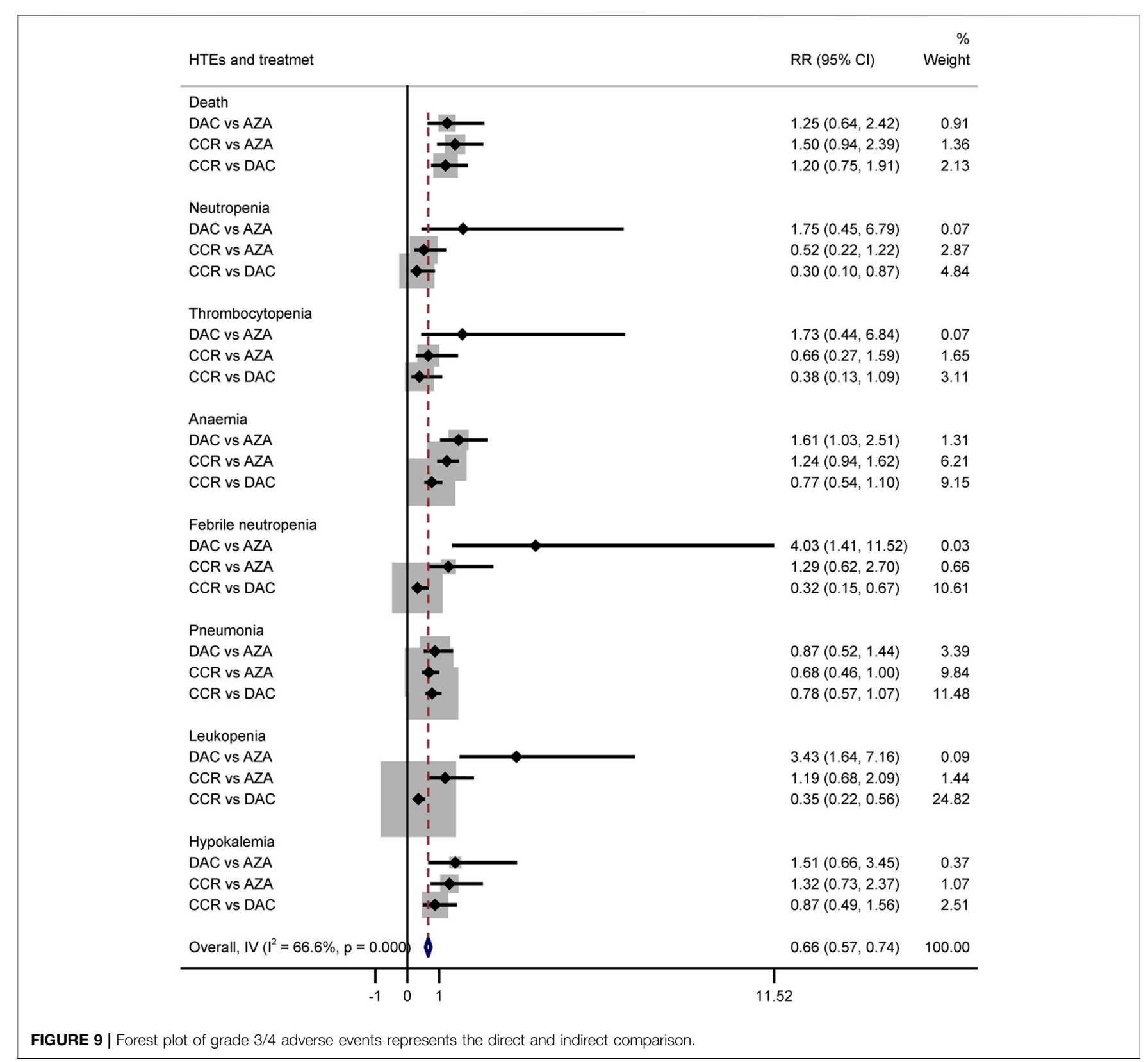

thrombocytopenia, anemia, and febrile neutropenia. Additionally, nonhematological adverse reactions such as pneumonia and hypokalemia also occurred in patients with HR-MDS or AML. In this study, a total of 2,135 patients from eight studies who received HMAs were included for analysis (Dombret et al., 2015; Fenaux et al., 2009; Fenaux et al., 2010; Kantarjian et al., 2006; Kantarjian et al., 2012; Lubbert et al., 2011; Seymour et al., 2017; Inc E et al., 2014). Subgroup of direct comparisons showed that, compared to CCR, AZA significantly increased the risk of grade $3 / 4$ neutropenia $(\mathrm{RR}=1.23,95 \% \mathrm{CI}$ : 1.13-1.35) and thrombocytopenia (RR $=1.14,95 \% \mathrm{CI}: 1.04-1.24)$ (Figure 7), and DAC increased the risk of grade $3 / 4$ neutropenia $(\mathrm{RR}=1.56,95 \% \mathrm{CI}: 1.34-1.81)$, thrombocytopenia $(\mathrm{RR}=1.41$, 95\% CI: $1.03-1.93)$, febrile neutropenia $(\mathrm{RR}=2.71,95 \% \mathrm{CI}$ :
1.22-6.01), and leukopenia $(\mathrm{RR}=2.49,95 \% \mathrm{CI}: 1.64-3.78)$ (Figure 8). In AML, AZA significantly increased the risk of grade $3 / 4$ neutropenia $(\mathrm{RR}=1.19,95 \% \mathrm{CI}: 1.03-1.37)$ (Supplementary Figure S2). In MDS, DAC increased the risk of grade $3 / 4$ neutropenia $(\mathrm{RR}=1.50,95 \% \mathrm{CI}$ : $1.25-1.79)$, febrile neutropenia $(\mathrm{RR}=4.00,95 \% \mathrm{CI}: 2.2-7.28)$, and leukopenia $(\mathrm{RR}=$ 2.86, 95\% CI: 1.29-6.34) (Supplementary Figure S5). There was no statistically significant difference found in other studied outcomes.

The results of the indirect comparison of AZA and DAC showed that DAC significantly increased the risk of high-grade anemia $(\mathrm{RR}=1.61,95 \% \mathrm{CI}: 1.03-2.51)$, febrile neutropenia $(\mathrm{RR}=$ 4.03, 95\% CI: $1.41-11.52)$, and leukopenia $(\mathrm{RR}=3.43,95 \% \mathrm{CI}$ : 1.64-7.16) compared with AZA (Figure 9). The results were the 


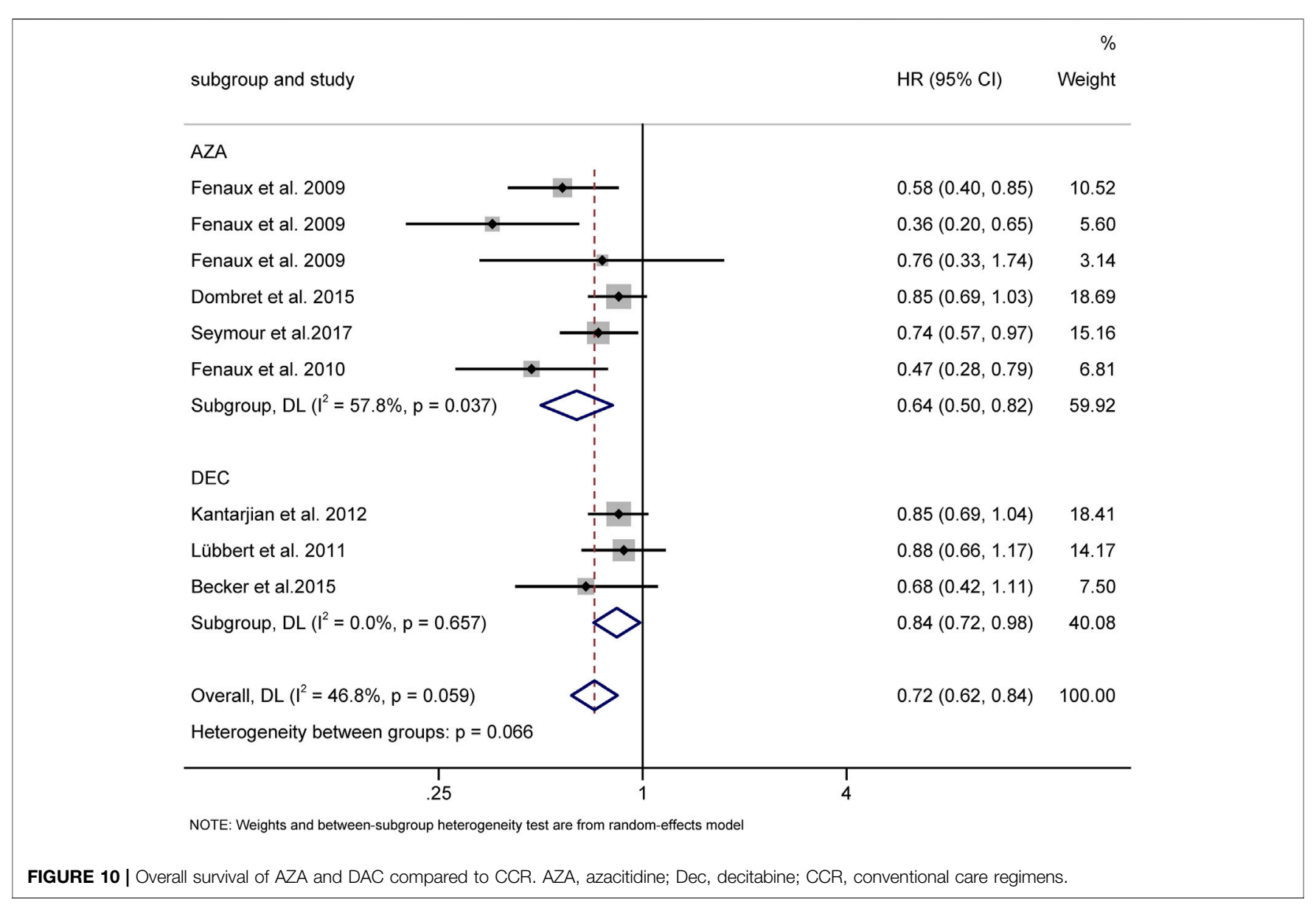

same in patients with AML (Supplementary Figure S3). There was no statistical significance in the association of other HTEs in groups treated with DAC compared with AZA.

\section{Comparison of Survival Between Decitabine and Azacitidine}

Seven RCTs were available for the analysis of median OS for HMAs vs. CCR (Becker et al., 2015; Dombret et al., 2015; Fenaux et al., 2009; Fenaux et al., 2010; Kantarjian et al., 2012; Lubbert et al., 2011; Seymour et al., 2017). Compared with CCR, both AZA $(\mathrm{HR}=0.64,95 \% \mathrm{CI} 0.50-0.82)$ and DAC $(\mathrm{HR}=0.84,95 \%$ CI 0.72-0.98) prolonged OS (Figure 10)

\section{DISCUSSION}

As common HMAs, AZA and DAC are widely used in clinical setting. Both of them have similar clinical effects. However, the clinical choice between them is controversial. In this systematic review and NMA, we aimed to evaluate the comparative efficacy and AEs of AZA and DAC in patients with HR-MDS and AML. In the direct comparisons of HMAs and CCR, we have demonstrated that both AZA and DAC are likely to have better outcomes compared to conventional care regimens (CCR) (including BSC, LDA, and IC) in terms of efficacy and
OS. NMA comparisons between AZA and DAC showed that there were no statistically significant differences in efficacy, while the efficacy sorting showed that DAC demonstrated a higher CR rate than AZA in patients with both AML and MDS. Overall, it seems that there is no superiority of one agent over the other in terms of response rates. However, with regard to the safety profile, patients receiving DAC experienced more frequent grade 3/4 cytopenia especially anemia, febrile neutropenia, and leukopenia than patients receiving AZA treatment.

A previous systematic review and NMA published in 2018 compared both HMAs agents to CCR in patients with MDS and has identified four trials. The results showed that HMAs overall improved survival and time to transformation or death (Almasri et al., 2018). Zhang et al. (2021) recently reported a meta-analysis of HMAs for elderly patients with AML. The results showed that HMAs improved the OS and CR rate compared with CCR and also increased the incidence of neutropenia, thrombocytopenia, and pneumonia. Another recent systematic review and NMA identified 1,086 elderly patients with AML from three RCTs to indirectly compare the efficacy and safety of DAC and AZA. The direct comparisons results showed that AZA significantly reduced mortality, while DAC was not compared to CCR. The indirect head-to-head comparisons showed that AZA significantly reduced the mortality rate and anemia. Patients treated with AZA were more likely to achieve CR compared to 
DAC (Wen et al., 2020). Liu et al. (2021) recently published an NMA which identified six RCTs with 1,072 MDS patients and three RCTs with 1,256 AML patients treated with HMAs. The results showed that, in MDS, AZA showed better AML-free survival, whereas DAC demonstrated higher CR and ORR, and AZA obtained better OS with lower toxicity. In AML, DAC had the possibility of achieving superior CR, ORR, and OS, while the toxicity was relatively higher. Taking these results together, all of the direct comparisons between HMAs and CCR are consistent with our findings. However, for the indirect comparisons of AZA and DAC, both of Almasri et al. (2018) and Wen et al. (2020)'s NMAs showed that AZA was more likely to improve $\mathrm{CR}$ compared to $\mathrm{DAC}$, despite being with lowcertainty evidence. This was different from our analysis. Our study showed that DAC had the possibility of achieving superior OR, CR, PR, and CRi than AZA, but there were no statistically significant differences in all response rates between the DAC and AZA groups. This finding is consistent with Zhang et al. (2021) and Liu et al.'s studies and a retrospective study of AZA versus DAC in patients with refractory anemia with excess blast (Salim et al., 2016). These differences can be interpreted as follows: a) heterogeneity and publication bias could not be obtained because of the small number of trials investigating each agent; b) our study mainly focused on higher-risk MDS and AML patients, while the previous study included all risk-stratified MDS patients, and the influence of different risk-stratified subgroups cannot be ruled out.

As for the comparisons of high grades AEs for AZA and DAC, previous retrospective studies indicated that patients who received AZA experienced less frequent episodes of grade 3/4 cytopenia and infectious episodes than DAC (Lee et al., 2013a; Lee et al., 2013b). Lee et al. reported more grade $3 / 4$ cytopenia ( 87 vs. $67 \%$, respectively) and infectious episodes in the DAC group (15.7 cytopenia episodes per 100 cycles vs. 11.8 infectious episodes per 100 cycles) (Lee et al., 2013b). Likewise, Je-Hwan Lee et al. found that high-grade neutropenia occurred more frequently in the DAC group than the AZA group (79.6 vs. $72.2 \%$ ) (Lee et al., 2013a). Similarly, in our study, DAC demonstrated a higher risk of grade $3 / 4$ anemia, leukopenia, and febrile neutropenia compared with AZA. In our study, we find that, compared with CCR, HMAs demonstrated higher grade $3 / 4$ cytopenia and infectious episodes. This finding is consistent with Gao et al. (2018)'s study.

However, no randomized trial has been ever conducted directly to compare AZA and DAC in AML patients, and a rare randomized trial has been carried out for higher-risk MDS patients. The overwhelming majority of RCTs included in this study were indirect comparisons, and low certainty of the evidence was found when comparing AZA and DAC. Therefore, more head-to-head clinical trials are still required. Additionally, given the limited number of included trials, heterogeneity, network consistency, and publication bias could not be adequately assessed. In studies of MDS patients, we mainly included studies with HR-MDS of more than $60 \%$. Data of some lower-risk patients were also included. This may lead to bias in the results. Optimally, a risk stratification model could be developed to analyze the effects of HMAs in different risk groups. Subgroup analysis could not be assessed due to the paucity of data. This analysis was not robust to sensitivity analyses based on meta-analysis model choice.

\section{CONCLUSION}

Compared to CCR, AZA and DAC can promote outcomes in patients with AML and HR-MDS. In patients with MDS, DAC demonstrated a higher $C R$ rate than AZA. There were no statistically significant differences between DAC and AZA in other outcomes and in patients with AML. However, AZA experienced lower frequent grade 3/4 leukopenia than patients receiving DAC treatment. For patients with AML or HR-MDS who are unfit for IC or HSCT, both AZA and DAC are available to use. Concerned about the lower hematological toxicity, AZA may be a better choice for elderly patients. However, the available indirect evidence comparing the two agents warrants very low certainty and cannot reliably confirm the superiority of either agent. More head-to-head prospective randomized clinical trials are needed. In the meantime, the choice of either agent should be driven by patients' preferences, drug availability, and costs.

\section{DATA AVAILABILITY STATEMENT}

The raw data supporting the conclusions of this article will be made available by the authors, without undue reservation.

\section{AUTHOR CONTRIBUTIONS}

JM and ZG reviewed the references. JM performed data analysis and wrote the manuscript. ZG supervised the manuscript.

\section{FUNDING}

This work is supported in part by the Jiangsu Province "333" project (BRA2019103) and Key Medical of Jiangsu Province (ZDXKB2016020). This paper had no prior presentations.

\section{SUPPLEMENTARY MATERIAL}

The Supplementary Material for this article can be found online at: https://www.frontiersin.org/articles/10.3389/fphar.2021.701690/ full\#supplementary-material 


\section{REFERENCES}

Almasri, J., Alkhateeb, H. B., Firwana, B., Sonbol, M. B., Damlaj, M., Wang, Z., et al. (2018). A Systematic Review and Network Meta-Analysis Comparing Azacitidine and Decitabine for the Treatment of Myelodysplastic Syndrome. Syst. Rev., 7(1), 144. doi:10.1186/s13643-018-0805-7

Arber, D. A. (2019). The 2016 Who Classification of Acute Myeloid Leukemia: What the Practicing Clinician Needs to Know. Semin. Hematol., 56 (2), 90-95. doi:10.1053/j.seminhematol.2018.08.002

Baker, S. G., and Kramer, B. S. (2002). The Transitive Fallacy for Randomized Trials: If a Bests B and B Bests C in Separate Trials, Is a Better Than C? BMC Med. Res. Methodol., 2, 13. doi:10.1186/1471-2288-2-13

Becker, H., Suciu, S., Rüter, B. H., Platzbecker, U., Giagounidis, A., Selleslag, D., et al. (2015). Decitabine versus Best Supportive Care in Older Patients with Refractory Anemia with Excess Blasts in Transformation (Raebt) Results of a Subgroup Analysis of the Randomized Phase Iii Study 06011 of the Eortc Leukemia Cooperative Group and German Mds Study Group (Gmdssg). Ann. Hematol., 94(12), 2003-2013. doi:10.1007/s00277-0152489-6

Cany, J., Roeven, M. W. H., Hoogstad-van Evert, J. S., Hobo, W., Maas, F., Franco Fernandez, R., et al. (2018). Decitabine Enhances Targeting of AML Cells by CD34+ Progenitor-Derived NK Cells in NOD/SCID/IL2Rgnull Mice. Blood, 131(2), 202-214. doi:10.1182/blood-2017-06-790204

Cheson, B. D., Bennett, J. M., Kantarjian, H., Pinto, A., Schiffer, C. A., Nimer, S. D., et al. 2000). Report of an International Working Group to Standardize Response Criteria for Myelodysplastic Syndromes. Blood, 96(12), 3671-3674. doi:10.1182/blood.V96.12.3671

Cipriani, A., Higgins, J. P. T., Geddes, J. R., and Salanti, G. (2013). Conceptual and Technical Challenges in Network Meta-Analysis. Ann. Intern. Med., 159(2), 130-137. doi:10.7326/0003-4819-159-2-201307160-00008

Creutzig, U., and Kaspers, G. J. L. (2004). Revised Recommendations of the International Working Group for Diagnosis, Standardization of Response Criteria, Treatment Outcomes, and Reporting Standards for Therapeutic Trials in Acute Myeloid Leukemia. Jco, 22(16), 3432-3433. doi:10.1200/JCO.2004.99.116

Daly, M., and Paquette, I. (2019). Surveillance, Epidemiology, and End Results (Seer) and Seer-Medicare Databases: Use in Clinical Research for Improving Colorectal Cancer Outcomes. Clin. Colon Rectal Surg., 32(1), 061-068. doi:10.1055/s-0038-1673355

Dombret, H., Seymour, J. F., Butrym, A., Wierzbowska, A., Selleslag, D., Jang, J. H., et al. (2015). International Phase 3 Study of Azacitidine vs Conventional Care Regimens in Older Patients with Newly Diagnosed Aml with $>30 \%$ Blasts. Blood, 126(3), 291-299. doi:10.1182/blood-201501-621664

Fenaux, P., Mufti, G. J., Hellstrom-Lindberg, E., Santini, V., Finelli, C., Giagounidis, A., et al. (2009). Efficacy of Azacitidine Compared with that of Conventional Care Regimens in the Treatment of Higher-Risk Myelodysplastic Syndromes: A Randomised, Open-Label, Phase Iii Study. Lancet Oncol., 10(3), 223-232. doi:10.1016/s1470-2045(09)70003-8

Fenaux, P., Mufti, G. J., Hellström-Lindberg, E., Santini, V., Gattermann, N., Germing, U., et al. (2010). Azacitidine Prolongs Overall Survival Compared With Conventional Care Regimens in Elderly Patients With Low Bone Marrow Blast Count Acute Myeloid Leukemia. Jco, 28(4), 562-569. doi:10.1200/ JCO.2009.23.8329

Furukawa, T. A., Cipriani, A., Barbui, C., Brambilla, P., and Watanabe, N. (2005). Imputing Response Rates from Means and Standard Deviations in MetaAnalyses. Int. Clin. Psychopharmacol., 20(1), 49-52. doi:10.1097/00004850200501000-00010

Gao, C., Wang, J., Li, Ya., Zhao, H., Li, R., Hou, L., et al. (2018). Incidence and Risk of Hematologic Toxicities With Hypomethylating Agents in the Treatment of Myelodysplastic Syndromes and Acute Myeloid Leukopenia: A Systematic Review and Meta-Analysis. Clin. Lymphoma Myeloma Leuk., 97(34), e11860. doi:10.1097/MD.0000000000011860

Higgins, J. P. T., Jackson, D., Barrett, J. K., Lu, G., Ades, A. E., and White, I. R. (2012). Consistency and Inconsistency in Network Meta-analysis: Concepts and Models for Multi-arm Studies. Res. Syn. Meth., 3(2), 98-110. doi:10.1002/ jrsm.1044
Higgins, J. P. T., and Thompson, S. G. (2002). Quantifying Heterogeneity in a Meta-Analysis. Statist. Med., 21(11), 1539-1558. doi:10.1002/sim.1186

Hollenbach, P. W., Nguyen, A. N., Brady, H., Williams, M., Ning, Y., Richard, N., et al. (2010). A Comparison of Azacitidine and Decitabine Activities in Acute Myeloid Leukemia Cell Lines. PLoS One, 5(2, e9001), doi:10.1371/ journal.pone.0009001

Kantarjian, H., Issa, J.-P. J., Rosenfeld, C. S., Bennett, J. M., Albitar, M., DiPersio, J., et al. (2006). Decitabine Improves Patient Outcomes in Myelodysplastic Syndromes. Cancer, 106(8), 1794-1803. doi:10.1002/ cncr.21792

Kantariian, H. M., Thomas, X. G., Dmoszynska, A., Wierzbowska, A., Mazur, G., Mayer, J., et al. (2012). Multicenter, Randomized, Open-Label, Phase Iii Trial of Decitabine versus Patient Choice, with Physician Advice, of Either Supportive Care or Low-Dose Cytarabine for the Treatment of Older Patients with Newly Diagnosed Acute Myeloid Leukemia. Jco, 30(21), 2670-2677. doi:10.1200/ JCO.2011.38.9429

Lee, J.-H., Choi, Y., Kim, S.-D., Kim, D.-Y., Lee, J.-H., Lee, K.-H., et al. (2013a). Comparison of 7-day Azacitidine and 5-day Decitabine for Treating Myelodysplastic Syndrome. Ann. Hematol., 92(7), 889-897. doi:10.1007/ s00277-013-1702-8

Lee, Y.-G., Kim, I., Yoon, S.-S., Park, S., Cheong, J. W., Min, Y. H., et al. (2013b). Comparative Analysis Between Azacitidine and Decitabine for the Treatment of Myelodysplastic Syndromes. Br. J. Haematol., 161(3), 339-347. doi:10.1111/ bjh. 12256

Liu, W., Zhou, Z., Chen, L., and Wang, X.(2021). Comparison of Azacitidine and Decitabine in Myelodysplastic Syndromes and Acute Myeloid Leukemia: A Network Meta-Analysis, Clin. Lymphoma Myeloma Leuk., 21(6), e530-e544. doi:10.1016/j.clml.2021.01.024

Lübbert, M., Suciu, S., Baila, L., Rüter, B. H., Platzbecker, U., Giagounidis, A., et al. (2011). Low-dose Decitabine versus Best Supportive Care in Elderly Patients With Intermediate- or High-Risk Myelodysplastic Syndrome (Mds) Ineligible for Intensive Chemotherapy: Final Results of the Randomized Phase Iii Study of the European Organisation for Research and Treatment of Cancer Leukemia Group and the German Mds Study Group. Jco, 29(15), 1987-1996. doi:10.1200/ JCO.2010.30.9245

Lyko, F., and Brown, R. (2005). DNA Methyltransferase Inhibitors and the Development of Epigenetic Cancer Therapies. J. Natl. Cancer Inst., 97(20), 1498-1506. doi:10.1093/jnci/dji311

Menzin, J., Lang, K., Earle, C. C., Kerney, D., and Mallick, R. (2002). The Outcomes and Costs of Acute Myeloid Leukemia Among the Elderly. Arch. Intern. Med. 162(14), 1597-1603. doi:10.1001/archinte.162.14.1597

Niño-Serna, L. F., Acosta-Reyes, J., Veroniki, A.-A., and Florez, I. D. (2020). Antiemetics in Children with Acute Gastroenteritis: A Meta-Analysis. Pediatrics, 145(4, e20193260). doi:10.1542/peds.2019-3260

Pfeilstöcker, M., Tuechler, H., Sanz, G., Schanz, J., Garcia-Manero, G., Solé, F., et al. (2016). Time-Dependent Changes in Mortality and Transformation Risk in Mds. Blood, 128(7), 902-910. doi:10.1182/blood-2016-02-700054

Salanti, G., Ades, A. E., and Ioannidis, J. P. A. (2011). Graphical Methods and Numerical Summaries for Presenting Results from Multiple-Treatment MetaAnalysis: An Overview and Tutorial. J. Clin. Epidemiol., 64(2), 163-171. doi:10.1016/j.jclinepi.2010.03.016

Salim, O., Toptas, T., Avsar, E., Yucel, O. K., Ozturk, E., Ferhanoglu, B., et al. (2016). Azacitidine versus Decitabine in Patients with Refractory Anemia with Excess Blast-Results of Multicenter Study. Leuk. Res., 45, 82-89. doi:10.1016/ j.leukres.2016.04.003

Santini, V., Alessandrino, P. E., Angelucci, E., Barosi, G., Billio, A., Di Maio, M., et al. (2010). Clinical Management of Myelodysplastic Syndromes: Update of Sie, Sies, Gitmo Practice Guidelines. Leuk. Res., 34(12), 1576-1588. doi:10.1016/ j.leukres.2010.01.018

Sanz, G. F. (2019). In Mds, Is Higher Risk Higher Reward? Hematol. Am Soc Hematol Educ Program, 2019(1), 381-390. doi:10.1182/ hematology.2019000042

Seymour, J. F., Döhner, H., Butrym, A., Wierzbowska, A., Selleslag, D., Jang, J. H., et al. (2017). Azacitidine Improves Clinical Outcomes in Older Patients with Acute Myeloid Leukaemia With Myelodysplasia-Related Changes Compared With Conventional Care Regimens. BMC Cancer, 17(1), 852. doi:10.1186/ s12885-017-3803-6 
Shallis, R. M., Wang, R., Davidoff, A., Ma, X., and Zeidan, A. M. (2019). Epidemiology of Acute Myeloid Leukemia: Recent Progress and Enduring Challenges. Blood Rev., 36, 70-87. doi:10.1016/j.blre.2019.04.005

Silverman, L. R., Demakos, E. P., Peterson, B. L., Kornblith, A. B., Holland, J. C., Odchimar-Reissig, R., et al. (2002). Randomized Controlled Trial of Azacitidine in Patients with the Myelodysplastic Syndrome: A Study of the Cancer and Leukemia Group B. Jco, 20(10), 2429-2440. doi:10.1200/ jco.2002.04.117

Stone, R. M. (2009). How I Treat Patients with Myelodysplastic Syndromes. Blood, 113(25), 6296-6303. doi:10.1182/blood-2008-09-038935

Stresemann, C., and Lyko, F. (2008). Modes of Action of the DNA Methyltransferase Inhibitors Azacytidine and Decitabine. Int. J. Cancer, 123(1), 8-13. doi:10.1002/ijc.23607

Wen, B., You, W., Yang, S., and Du, X. (2020). Indirect Comparison of Azacitidine and Decitabine for the Therapy of Elderly Patients with Acute Myeloid Leukemia: A Systematic Review and Network Meta-Analysis. Exp. Hematol. Oncol., 9, 3. doi:10.1186/s40164-020-00160-8

Zhang, R. J., Zhai, J. H., Zhang, Z. J., Yang, L. H., Wang, M. F., and Dong, C. X. (2021). Hypomethylating Agents for Elderly Patients with Acute Myeloid
Leukemia: A Prisma Systematic Review and Meta-Analysis. Eur. Rev. Med. Pharmacol. Sci., 25(6), 2577-2590. doi:10.26355/eurrev_202103_25421

Conflict of Interest: The authors declare that the research was conducted in the absence of any commercial or financial relationships that could be construed as a potential conflict of interest.

Publisher's Note: All claims expressed in this article are solely those of the authors and do not necessarily represent those of their affiliated organizations, or those of the publisher, the editors and the reviewers. Any product that may be evaluated in this article, or claim that may be made by its manufacturer, is not guaranteed or endorsed by the publisher.

Copyright (C) $2021 \mathrm{Ma}$ and Ge. This is an open-access article distributed under the terms of the Creative Commons Attribution License (CC BY). The use, distribution or reproduction in other forums is permitted, provided the original author(s) and the copyright owner(s) are credited and that the original publication in this journal is cited, in accordance with accepted academic practice. No use, distribution or reproduction is permitted which does not comply with these terms. 